\title{
Study of Expressway Service Area Function Expansion
}

\author{
LiangZhou ${ }^{1}$, XingYang ${ }^{1}$, and Hongxi Liu ${ }^{2 *}$ \\ ${ }^{1}$ Transport Planning and Research Institute, Beijing, 100028, China \\ ${ }^{2}$ Section of Foreign Language, Department of Basic Studies, Criminal Investigation Police University of China, Shenyang, Liaoning, \\ 110854, China
}

\begin{abstract}
With the rapid development of economy and society, in the face of an increasingly large expressway consumer group, the expansion and upgrading of the expressway service area to marketization and industrialization is the only way for the sustainable development of the service area. The service area should be adapted to local conditions when expanding functions, and be expanded in a targeted manner according to the characteristics of each service area.
\end{abstract}

\section{Introduction}

The expressway service areas mainly provide catering, rest, accommodation, shopping, entertainment, medical treatment, communication, information consultation for drivers and passengers, and provide parking and refueling for the vehicles[1][2][3][4][5][6][7][8][9]. The expressway service area is one of the important signs for measuring the completeness of the supporting facilities of the expressway. The service area plays an important role in reducing traffic accidents on the expressway, optimizing the expressway environment, and improving the operational efficiency and social benefits of the expressway. The service area can help the drivers and passengers get rest during the journey, thereby restoring energy and stamina, to facilitate traffic safety. The service area also provides numerous employment opportunities for local people. The local tourism, services, communications, commerce and finance will also be promoted by the development of service area.

\section{Situation and problems of the highway service area}

\subsection{History and current situation}

In the past thirty years, government issued a series of supportive policies to encourage and promote the rapid development of highways, since then, the service area also kept up with the pace of the rapid development of highways. The initial service area mainly provided basic catering, parking, toilet and other services which are essential to ensure driving safety, ease travel fatigue, and improve vehicle efficiency.

In recent years, with the continuous expansion of highways, the demand for travel and the pursuit for a better life are increasing. The traditional service area cannot meet the multi-format and personalized needs for people. The service area planning and design began to target multiple business forms and high quality services. At present, leisure, entertainment, special catering, cultural communication and information services have been formed. The service area has expanded in scale and the service level has been continuously improved.

\subsection{The problems}

\subsubsection{Small scale.}

The service area size is relatively small. In the service area design process, the lack of objectivity of the traffic volume, understanding and analysis models, led to design errors. After the completion of the service area, there may be insufficient parking spaces, long time queuing bathroom, long time waiting for refueling and other phenomena, reducing the driver and passenger experience.

\subsubsection{Lack of user's needs.}

Many service areas are designed without considering the functional needs of the service objects, which are difficult to meet the needs of the users. Some of the service areas have a large green area which occupied the parking lot. Some facilities in the service area, such as accommodation facilities, are vacant for a long time. Other service areas are too small but the decoration is too luxurious. Thus the function of service is not well reflected.

\subsubsection{Low service level.}

Management is limited to basic service items, and the service level is not high. Currently, most of the operating items of the service area are still fueling, catering,

*Corresponding author's e-mail: 1187488@qq.com 
accommodation. Most of the operators of the business in the service area are individuals who provide low quality service, leading to the lower service level of the service area. Thus the satisfaction rate of the passengers is not high.

\section{New function expansion in the service area}

"Service areat" refers to the integration of the expressway service area with traditional functions, and the transformation and upgrade of the expressway service area by means of integrated layout, reconstruction of business models, optimization of design, and updating of service methods.

\subsection{Service area + tourism.}

This kind of service area is generally the integration of the rich tourism resources around or along the road [6], based on traditional functions, and combined with the service area to create a "service area + tourism". The size of service area, building size, geographical features, resource endowments, and peripheral industries are not the same. The factors mentioned above determine the differences in the service area. The geographic locations where the service area, natural resources have become the core area of service differentiation. Therefore, the basic functions of the existing service area can be optimized, and the service image, brand influence, operating ability, and cultural marketing can be improved. The service area should be re-planed. Regions such as supermarkets, stores and toilets are strictly divided. And tourist parks are built in idle areas. At the same time, large service areas with huge areas and connected to the outside world are built into ecological parks or forest parks and other distinctive service areas.

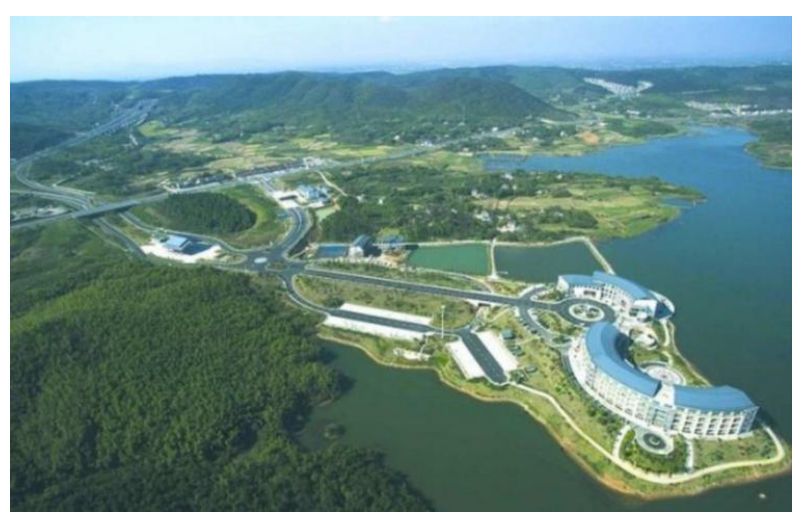

Figure 1. Landscape of service area in Jiangsu Province

\subsection{Service area + logistics}

Such service areas have the function of logistics distribution. Such service area should be easily accessible, wide radiation range, and land sufficient. These service areas can be built into a passenger turnover. Logistics parks through the surrounding area can be built.
Logistics enterprises around the logistics park are attracted in the service area. And then realize the industrial agglomeration effect of the logistics enterprises centered on the service area. Meanwhile, the service area can process and sell agricultural products in surrounding villages and towns. The service area can be used as a basic exhibition platform for information release, which provides the information about the market demand and supply to the surrounding area. Such service area also should establish logistics information data platform for the passing vehicles. The service area can provide storage, distribution, turnover, distribution and other basic information for logistics companies around the service area. The first freight theme expressway service area starts construction in Guangdong Province [10].

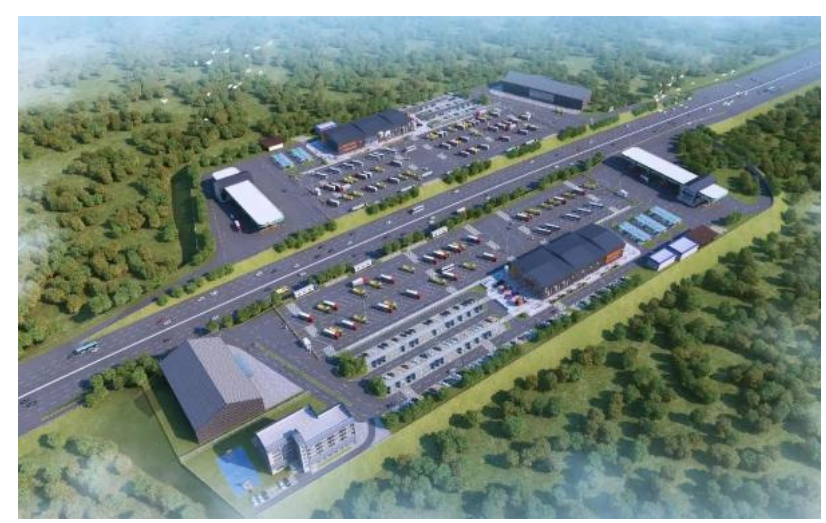

Figure 2. Sketch of freight theme service area in Guangdong Province

\subsection{Service area + emergency guarantee}

Such service areas should also have emergency support functions in response to emergencies. With the extension of the highway network, the overall risk of emergencies caused by climatic factors, major traffic accidents and major public health events (such as novel coronavirus pneumonia sweeping the world in 2020) has greatly increased, requiring emergency response in service areas. The service areas have the advantages of information distribution, rapid response, reserve materials, resettlement personnel, and other aspects in emergency support. The service areas need to set a convenient channel to link up with the outside road network in order to respond to emergency situations, and also need to reserve the appropriate content and number of emergency equipment and materials. 


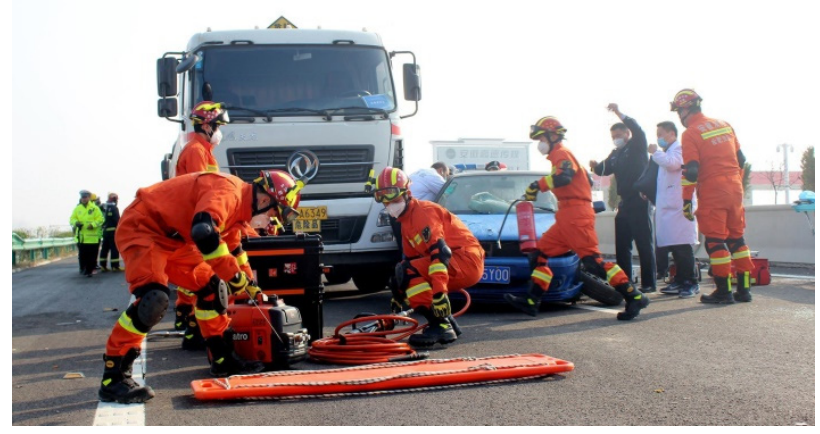

Figure 3. Traffic accident emergency drilling of service area in Anhui Province[11]

\subsection{Service area + poverty alleviation}

This type of service area has the distribution function of agricultural products [12]. For agricultural products to realize the time and space value, they must be stored and transferred at the node, and this node must be convenient in transportation and large area. The service area along the highway has this advantage, so the agricultural product distribution business can be carried out in the service area. That is, the agricultural products within the effective range of the highway were brought together to service area. The agricultural trade was implemented within the service area. The circulation of commodities without affecting the operation of the highway can be strengthened. By means of sales platform service area, the accurate poverty goal was achieved.

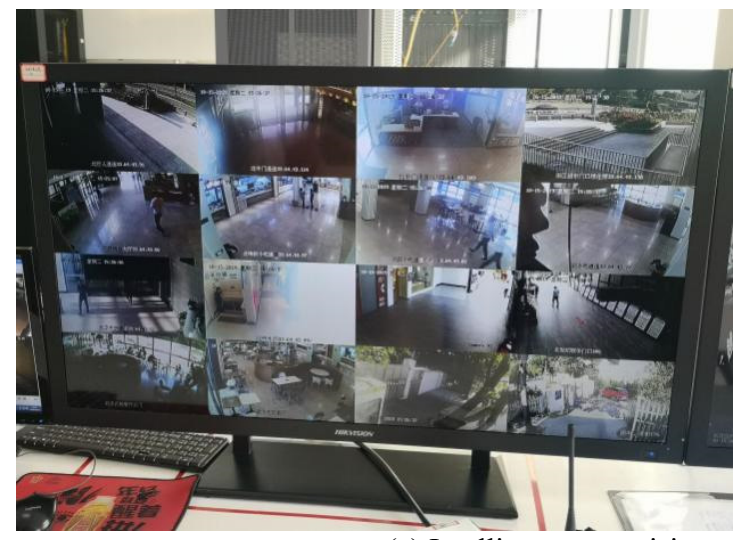

(a) Intelligent supervision

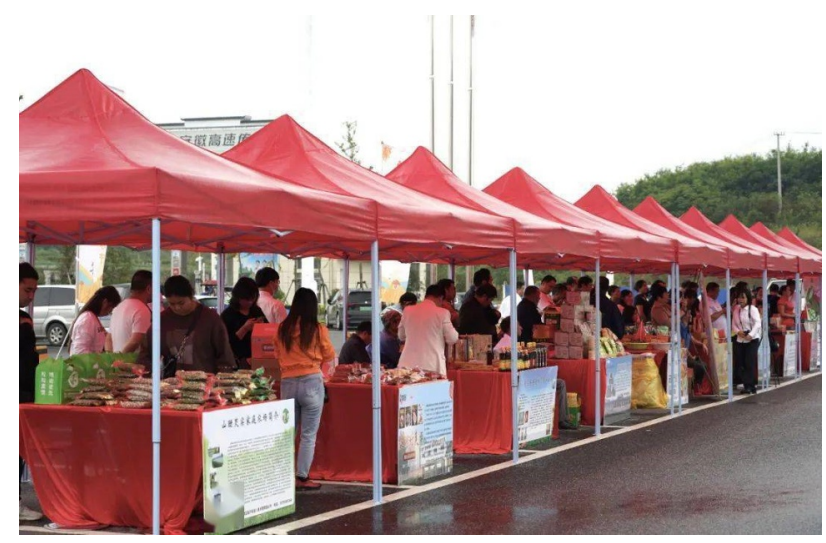

Figure 4. Agricultural products counter for poverty alleviation in service area in Anhui Province

\subsection{Service area + Smart Big Data}

The smart service area can provide a better service experience for passing drivers and passengers. Through big data, online tracking and mining analysis of people flow, traffic flow, logistics turnover, behavior habits, consumption preferences, etc. The service area can actively recommend the available service resource information in front of the driving vehicle, and realize the intelligent guidance of the vehicles. The dynamic adjustment of service resources realized through big data analysis. With the help of big data, the service area can not only provide the public with accurate services in the service area resources before and during travel, but also alleviate service area and road congestion. Thereby, the service area can provide better quality and more humanized travel services for passing vehicles and personnel.

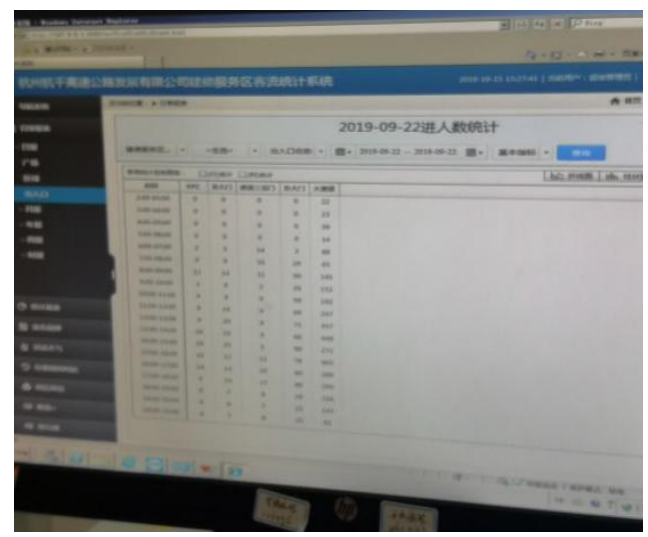

(b) big data system

Figure 5. Service area + Smart Big Data in ZheJiang Province

\section{Conclusions and recommendations}

With the rapid development of economy and society, in the face of an increasingly large expressway consumer group, the expansion and upgrading of the expressway service area to marketization and industrialization is the only way for the sustainable development of the service area. If we want to achieve a positive interaction between social and economic benefits, we need to pay attention to the following points.

The service area should be adapted to local conditions when expanding functions, and be expanded in a targeted manner according to the characteristics of each service area. "Service area + tourism" mode highly relies on the natural environment requirements. The most important needs are to properly handle the relationship between man and nature, and to reduce the maximum damage to 
the natural environment. "Service area + logistics" requires a combination of logistics industry development in the region. It can be effective in combination with reasonable industrial layout on the composition of the logistics network. "Service area + emergency guarantee" mode needs the service area management initiative with the local police and fireman to establish a compensation mechanism in order to utilize the application of disaster prevention and disaster relief resources. "Service area + poverty alleviation" requires local governments to help neighboring merchants and farmers to exhibit the agricultural products. It is possible to achieve the goal of poverty alleviation only through the exhibitions and sales that increase farmers' income. "Service area + Smart Big Data" need reexamine the information construction of the service area, so that it can achieve the goal of internetization and big data, together with network.

China's land resources are becoming increasingly tight, so the land need for the expansion of the highway service area may be the biggest obstacle. Due to the strict land restrictions, the expansion of new functions in the service area has been greatly restricted, resulting in the waste of some resources and affecting the economic development of the surrounding areas. Therefore, the transportation department should strive for more land targets.

At this stage, the investment and financing channels of the expressway service area are limited. In the future, greater efforts should be made to attract social capital, especially in the early stage of service area construction, service area reconstruction and expansion.

\section{Reference}

1. Takashi. S, Kiko. Y.K., Hirokazu. M., Takashi. U. (2011) New Measure of the Level of Service for Basic Expressway Segments Incorporating Customer Satisfaction 6th International Symposium on Highway Capacity and Quality of Service Stockholm. In rocedia Social and Behavioral Sciences. Sweden. pp.57-68

2. Jaewook. J., Changyoon J., Taehoon. H., and Hyo. S.P. (2016) Model for Evaluating the Financial Viability of the BOT Project for Highway Service Areas in South Korea. J. Manage. Eng., 32:1-13

3. Mahmoud. A, Iraj B., (2015) Modeling Site Selection for Roadside Service Area Complexes Using Dynamic Programming and Site Characters. Jurnal UMP Social Sciences and Technology Management. No.3, pp. 943-954.

4. Timothy J. Gates, Peter T. Savolainen, Tapan K. Datta, and Ryan G. Todd (2013) Transportation Research Record: Journal of the Transportation Research Board, No. 2346, pp. 63-71.

5. Naoko. N, Akira K. and Hideo A. (2012) World Environmental and Water Resources Congress 2012, pp. 2795-2802.

6. U.S. Department of Transportation.(1988) Manual on Uniform Traffic Control Device for Streets and Freeways.
7. Kelley K. Pécheux, Kathryn J. Chen, John Farbry, Jr., and Stephen A. Fleger. (2002) Model Development for National Assessment Of Commercial Vehicle Parking.

8. Dennis. A. and James. R. (1981) Transportation Research Record, Landscape and environmental design, No. 822, pp.1-6.

9. Trucking Research Institute, Apogee Research Inc., Wilbur Smith Associates. (1996) Commercial Driver Rest \& Parking Requirements: Making Space for Safety.

10. https://www.sohu.com/a/437663204_120214184

11. http://www.aqsc.cn/tupian/201811/27/c92999.html

12. https://www.sohu.com/a/421833889_99904161 